Revista de Economia Política, vol. 37, no 2 (147), pp. 324-342, abril-junho/2017

\title{
Interesses financeiros e captura do Estado no Brasil
}

\author{
Financial interests and the capture of the State in Brazil
}

MARCUS IANONI*

RESUMO: O trabalho explora a avaliação de Bresser-Pereira (2007) de que a política macroeconômica brasileira exprime a captura do Estado por uma coalizão de interesses rentistas e financistas, que também influencia a regulação financeira. Para tanto, analisa duas agências de relacionamento com investidores, do Banco Central e do Tesouro Nacional, e uma agência de promoção de investimentos formada por reguladores e regulados. Argumenta que essas agências estreitam a comunicação e canais de formulação de políticas entre reguladores e regulados; atestam a influência das instituições financeiras nas decisões de políticas públicas; e corporificam convergência de interesses entre investidores financeiros e Estado. Conclui avaliando que a tesa da captura da política macroeconômica é plausível e deve ser pesquisada de modo sistêmico.

PALAVRAS-CHAVE: Interesses financeiros; teoria da captura; relações com investidores; Banco Central; Tesouro Nacional; Best Brazil.

ABSTRACT: The work explores the evaluation of Bresser-Pereira (2007) of which the Brazilian macroeconomic policy expresses the capture of the State by a coalition of rentiers and financiers interests, which also influences financial regulation. To this end, analyzes two investor relations agencies, of the Central Bank and of the National Treasury, and an investment promotion agency formed by regulators and regulated. Argues that these agencies strengthen communication and policymaking channels between regulators and regulated; attest to the influence of financial institutions on public policy decisions; and carry convergence of interests among financial investors and State. Concludes by assessing the thesis of macroeconomic policy capture is feasible and should be researched in a systemic way.

KEYWORDS: Financial interests; capture theory; investor relations; Central Bank; National Treasure; Best Brazil.

JEL Classification: E5; G0; F3.

\footnotetext{
* Professor do Departamento de Ciência Política da Universidade Federal Fluminense. E-mail: marcus. ianoni@gmail.com. Submetido: 17/Março/2016; Aprovado: 5/Abril/2016.
} 


\section{INTRODUÇÃO}

O enfoque hegemônico da questão fiscal no Brasil, veiculado nos meios de comunicação de massa, identifica nas despesas do setor público não-financeiro, sobretudo da União, mas também de entes federativos subnacionais, a principal fonte das dificuldades orçamentárias do Estado. ${ }^{1}$ Mas Bresser Pereira (2007, p. 189) avalia que a causa principal do desequilíbrio fiscal brasileiro está na elevadíssima taxa de juros de curto prazo implementada pelo Banco Central do Brasil (BCB). ${ }^{2}$ Essa avaliação contraria a visão de que os problemas fiscais localizam-se no setor público não financeiro. João Sayad (2005) vai na mesma direção: "O discurso oficial ainda é de que o setor fiscal é que pressiona o setor monetário. $\mathrm{Na}$ verdade é o contrário, o setor monetário é que pressiona o fiscal. [...] a dívida pública cresceu em função da política de juros altos e não pelas pressões fiscais”. Para Bresser-Pereira (doravante B-P) o Estado brasileiro, em especial o BCB, está capturado por uma coalizão política que se beneficia, por um lado, de um dos mais altos juros reais do mundo e, por outro, de um câmbio sobrevalorizado. ${ }^{3}$ Compõem esta coalizão política os rentistas, o setor financeiro, o grande capital investido nos serviços públicos - todos interessados nos juros altos, que indexam parte relevante da dívida pública mobiliária interna, e nos preços monopolistas das empresas multinacionais, beneficiadas pelo câmbio baixo.

A tese de B-P será aqui a hipótese de pesquisa. A hipótese da captura da política macroeconômica e do BCB por grupos organizados de interesse financeiro permite um diálogo, tão necessário quanto pouco explorado, nas ciências sociais brasileiras, entre economia política, ciência política e sociologia política, no que diz respeito à análise das políticas monetária e fiscal. Esta pesquisa exploratória investiga a existência de uma causa política para a compreensão das altas taxas de juros reais implementadas no Brasil e, por conseguinte, para o desequilíbrio fiscal. Por ser exploratória, não visa confirmar a hipótese de B-P, mas avançar alguns passos para defender sua plausibilidade e corroborá-la.

O caminho metodológico adotado para perseguir o objetivo será a análise institucional de canais de comunicação e/ou de parceria privado-público de marketing financeiro, que têm aproximado e vinculado grupos de interesse rentista e financista a agências-chaves da área econômica do Estado brasileiro e vice-versa. Considera-se relevante evidenciar empiricamente a coexistência entre, por um lado,

\footnotetext{
${ }^{1}$ Ver, e.g., em Gazeta Mercantil, 9/11/2006, matéria de S. Cavalcanti sobre evento que debateu o desequilíbrio fiscal.

${ }^{2}$ Definição de desequilíbrio fiscal no Brasil: “uma carga tributária incompatível com o nível de desenvolvimento econômico do país, que, no entanto, não impede que a poupança pública seja negativa e que os índices de endividamento do Estado, principalmente o índice juros pagos pelo Estado/PIB, sejam altos demais" (B-P, 2007, p. 169).

${ }^{3}$ Desde a estabilização monetária de 1994, o Brasil tem, frequentemente, ocupado a posição de campeão mundial em taxas de juros reais.
} 
estreitos vínculos institucionais entre reguladores e regulados, nas áreas monetária e fiscal, e, por outro, decisões regulatórias que favorecem os últimos.

Serão analisadas três iniciativas institucionais de relações com investidores (RI) - sendo a terceira delas (Best) também de marketing financeiro. São elas: a Gerência-Executiva de Relacionamento com Investidores do Banco Central do Brasil - Gerin (BCB); a Gerência de Relacionamento Institucional da Secretaria do Tesouro Nacional - Gerin (STN); e o Brazil Excellence in Securities Transactions (Best), composto, na sua face empresarial, por ANBID (Associação Nacional dos Bancos de Investimento), BM\&F (Bolsa de Mercadorias e Futuros), BOVESPA (Bolsa de Valores de São Paulo) e CBLC (Companhia Brasileira de Liquidação e Custódia); pelo setor público, participam o BCB, o STN e a Comissão de Valores Mobiliários (CVM). ${ }^{4}$

Agências de RI vêm sendo implantadas nos países emergentes desde as crises financeiras e cambiais de meados dos anos 1990, particularmente quando, em 1994, o Banco do México foi forçado a desvalorizar o peso, devido à fuga de capitais e à perda de reservas internacionais. Uma das lições extraídas da crise foi que sua extensão se agravou pela má qualidade das informações disponibilizadas para os investidores, tanto por fontes públicas e oficiais (como o governo mexicano e o FMI), quanto pelo mercado. Entre as informações deficitárias, estariam as relacionadas às reservas internacionais. ${ }^{5}$ Nesse contexto, já em 1995, o governo mexicano criou a Oficina de Relación com Inversionistas, vinculada à Secretaría de Hacienda y Crédito Público, com apoio do FMI e do IIF. ${ }^{6}$

Desde então, uma série de programas de RI vêm sendo implementados em diversos países emergentes, vinculando instituições e organizações internacionais da comunidade financeira a instituições e organizações domésticas, públicas e privadas, das áreas monetária e financeira. No Brasil, criaram-se agências e staff burocrático específicos para RI, que estruturam uma comunicação de mão dupla entre BCB e investidores em portfólio e emissor (STN) e credores de títulos da dívida pública. Embora BCB e STN sejam agências que, pela própria natureza de suas atividades, lidam com o mercado financeiro, a globalização tem induzido a uma política macroeconômica liberal e a um estreitamento de laços entre investidores em carteira e Estado. Um dos resultados dessas tendências, no Brasil, têm sido o aumento do endividamento público e a volumosa transferência de recursos do Estado para os seus credores privados ${ }^{7}$. Por outro lado, o crescimento da dívida pública não tem sido direcionado ao financiamento do desenvolvimento econômico. ${ }^{8}$

\footnotetext{
${ }^{4}$ Em março de 2008, foi fechado acordo de fusão entre BOVESPA e BM\&F, que resultou na criação da "Nova Bolsa", ou BM\&FBOVESPA.

${ }^{5}$ Consultar Camdessus (1995), Fischer (2004, pp. 127 e 145) e Businesseek, September, 2003, disponível em www.businessweek.com/magazine/content/03_39/b3851710.htm, visitado em 25/3/2008.

${ }^{6} \mathrm{O}$ sítio da ORI do governo mexicano é bit.ly/1QxBMox (visitado em 8/3/2016).

${ }^{7}$ Embora, nos últimos anos, a relação dívida líquida/PIB esteja declinando, é fato que ela ainda está significativamente acima do nível em que se encontrava no período pré-Plano Real.

8 “O crescimento da relação dívida pública sobre o produto transformou o Estado no grande tomador
} 
Seguem-se três seções. A primeira delimita a abordagem teórica, formula o problema e as hipóteses. A segunda contextualiza a institucionalização das relações com investidores, sob influência da comunidade financeira internacional, em Estados de países emergentes e analisa as três agências selecionadas para estudo. A última seção sintetiza as conclusões.

\section{POLÍTICA MACROECONÔMICA E INTERESSES FINANCEIROS}

Os fundamentos teóricos deste trabalho provêm da análise dos grupos de interesse, da teoria econômica da regulação (teoria da captura) e do neoinstitucionalismo. A pesquisa dos grupos de interesse advém da literatura política norte-americana sobre o pluralismo. Entre outros temas, ela aborda a influência dos grupos de interesse no processo decisório das políticas públicas. A definição de grupos de pressão de Pasquino (1984) contempla o entendimento que aqui se faz do termo. Eles são organizados, mas distintos de partidos políticos, embora pretendem influenciar a distribuição de recursos em uma sociedade. ${ }^{9}$ Estudos sobre a influência dos grupos de interesse nas decisões públicas costumam investigar três questões: quem atua, que interesses possui e que estratégias adota. Este trabalho ocupa-se dos grupos de interesse financeiro, nacional e internacionalmente, no que diz respeito à sua influência sobre as autoridades monetária e fiscal do Estado brasileiro. No que diz respeito ao interesse financeiro internacional, observa como, através do FMI, foram implementados os programas de relações com investidores no BCB e na STN e o que eles executam.

Desde o câmbio fixo (1994-1998), prosseguindo com o câmbio flutuante (1999 até hoje), os juros altos têm sido uma característica da macroeconomia brasileira, assim como os elevados spreads bancários. Outra particularidade tem sido a tendência de sobrevalorização do câmbio, que prejudica a indústria manufatureira, as exportações e induz a déficits em transações correntes. A atual política macroeconômica funda-se no tripé constituído por câmbio flutuante em regime de livre fluxo de capitais, metas de inflação (perseguidas por elevadas taxas de juros reais) e realização de superávit primário, que resultam três grandes preços macroeconômicos: a taxa de inflação (baixa), a taxa de juros (alta) e a taxa de câmbio (baixa). Devido a isso, B-P (2007, p. 235) refere-se à configuração, em linhas gerais, de um modelo macroeconômico, proveniente da estabilização monetária de 1994.

Entre 1979 e 1994, a inflação foi o sintoma mais grave do desequilíbrio macroeconômico. Desde então, ele passa a ser a elevada taxa de juros (B-P, 2007, p. 191;

da poupança privada. Diante da enorme necessidade de financiamento do setor público, diminui a disponibilidade de recursos para serem destinados ao setor privado através do mercado de capitais" (BCB, 18/8/2003, Pronunciamento do Dr. Henrique Meirelles na Posse da Nova Diretoria da ANBID).

\footnotetext{
${ }^{9} \mathrm{Na}$ polêmica sobre o conceito de grupos de interesse, alguns preferem o termo grupo de pressão. Consultar (Salisbury, 1975).
} 
Garcia, 2003). ${ }^{10}$ Os capitais financeiro e rentista beneficiaram-se da alta inflação e continuam se beneficiando com as altas taxas de juro e outras políticas regulatórias destinadas aos investimentos em carteira. Entre outras medidas, as Resoluções 2689 e 2687, aprovadas pelo Conselho Monetário Nacional (CMN) em 2000, regulamentando o acesso de investidores estrangeiros ao mercado financeiro e de capitais, e a introdução, em 2002, do novo Sistema de Pagamentos Brasileiro impulsionam a liberalização financeira. O câmbio flutuante e a inflação baixa têm também estimulado o mercado de capitais, atraindo a ele investidores não residentes e locais. A liberalização dos fluxos de capitais, iniciada no governo Collor, aprofundou-se na presidência do BCB por Armínio Fraga (Freitas e Prates, 2001).

B-P avalia que as linhas gerais das políticas monetária, cambial e fiscal, implementadas desde 1994, têm favorecido, especialmente, os rentistas, o setor financeiro e as multinacionais, exprimindo a captura do Estado e do BCB por esses grupos de interesse. Ele estima a captura rentista, medida em juros sobretaxados pagos pelo Estado, em 4\% do PIB ${ }^{11}$. No mesmo sentido, os economistas Paulani e Teixeira (2007) e Cintra (2005) afirmam que os rentistas constituem a base do poder político e econômico no Brasil atual. ${ }^{12}$ Visando construir elos entre essas avaliações de economistas e a ciência política, o artigo investiga a hipótese da captura da política macroeconômica.

Há um debate sobre as altas taxas de juros existentes no Brasil. ${ }^{13}$ B-P levanta as seguintes explicações para isso: ${ }^{14}$ por faltar crédito do Estado (visão da ortodoxia convencional); pela taxa de equilíbrio "natural" ser alta (9\% reais), conforme Muinhos e Nakane (2006); para atrair capitais; devido à hipótese da incerteza jurisdicional (Arida, Bacha e Lara Resende, 2005); e pelo problema fiscal. ${ }^{15} \mathrm{E}$ refuta todas elas, identificando "causas melhores": a "diminuição [das taxas de juros] contraria diretamente os interesses dos rentistas e do setor financeiro, que lucram com juros altos, e das empresas multinacionais e dos concorrentes estrangeiros, que se beneficiam de câmbio baixo"; a hegemonia ideológica expressa na prática do confidence building; a indexação da taxa de juros a ela própria (da Selic à própria Selic); a política de alongamento da dívida pública praticada pelo BCB; e o fato de que a caderneta de poupança estabelecia uma taxa básica já alta para os pobres (6\% de juros reais).

\footnotetext{
${ }^{10}$ Mas nos anos 1980, as taxas de juros reais foram tão altas que os parlamentares constituintes as limitaram a $12 \%$ anuais. A Emenda Constitucional 40/2003 revogou essa limitação.

${ }^{11}$ Consultar B-P (2007, pp. 53, 65, 86, 103, 108, 176-7, 178, 265).

12 Consultar também Paulani (2003).

${ }^{13}$ Sobre a visão dos banqueiros para os juros altos, consultar bit.ly/1pdiaQ3 (visitado em 8/3/2016).Em geral, os especialistas atribuem várias causas aos elevados juros reais de curto prazo existentes no Brasil, e.g., Holland (2006) e Gambirasio (2006). Não se visa aqui fazer um balanço dessa literatura.

${ }^{14}$ Faz-se aqui uma síntese de B-P, op. cit., pp. 191-216.

${ }^{15}$ Essa explicação, B-P considera ser uma meia verdade, sendo, para ele, a causa principal do desequilíbrio fiscal a própria taxa de juros. ${ }^{19} \mathrm{Op}$. cit., p. 208.
} 
É possível evidenciar a influência política do setor financeiro na política macroeconômica em curso no Brasil, que seria um dos fatores explicativos das elevadas taxas de juro e também permitiria trazer mais luz para a compreensão de outras políticas regulatórias pró-indústria financeira implementadas pelo Estado? Essa questão remete aos dois próximos passos teóricos, a teoria da captura e a análise institucional.

A teoria da captura enraíza-se na pesquisa dos grupos de interesse, aplicando-a especificamente à análise da política regulatória. Stigler (1971) fez a formulação pioneira da teoria econômica da regulação, conhecida como teoria da captura. Ele afirma: "Regulation may be actively sought by an industry, or it may be thrust upon it. [...] as a rule, regulation is acquired by the industry and is designed and operated primarily for its benefit". ${ }^{21}$ Esse autor adota o pressuposto utilitarista de que o Estado é uma potencial fonte de recursos, cujo uso pode beneficiar ou prejudicar, seletivamente, indústrias e profissões. Sua teoria da captura visa explicar, em relação à regulação econômica (RE), quem receberá benefícios e quem arcará com os ônus, que forma ela terá e quais serão os seus efeitos sobre a alocação de recursos.

Tal como a teoria macroeconômica neoclássica, a teoria da captura pressupõe que os homens perseguem seus interesses e fazem-no de modo racional, o que permite prever e analisar os comportamentos dos agentes econômicos (Posner, 2004, p. 59). Uma decorrência comportamental do pressuposto da racionalidade é a busca da maximização dos lucros no mercado. Essa racionalidade é também verificada no sistema político, visto como instrumento para a realização de interesses de grupos sociais. A teoria da captura analisa o comportamento político com parâmetros da análise econômica. Dois tipos de atores insiders do sistema político são relevantes nessa análise: os políticos, tanto os representantes eleitos como os nomeados por eles, e os reguladores, membros da burocracia pública de carreira ou políticos (nomeados ou eleitos). Disso decorre a possibilidade de se analisar a RE como inserida em uma estrutura racional de oferta e demanda. Pelo lado da demanda estão os grupos de interesse ligados às diversas indústrias, outsiders que desejam RE em seu próprio benefício, conhecem os interesses dos políticos - dinheiro para financiar campanhas eleitorais, votos e cargos para seu séquito (nos setores privado ou público) - e lhes oferecem vantagens em troca de políticas regulatórias. No lado da oferta estão os políticos que, cientes de que os grupos de interesse querem RE a seu favor, dispõem-se a barganhá-la. Assim, estruturam-se as condições para a troca.

Stigler distingue quatro tipos de políticas regulatórias que uma indústria pode obter do Estado: subvenção direta em dinheiro; controle sobre a entrada de novos concorrentes; regras que prejudicam produtos ou serviços substitutos ou que favorecem produtos e serviços complementares aos da indústria interessada na regulamentação; e fixação de preços, por exemplo, das taxas de juro, câmbio, inflação, spreads e tarifas bancárias. ${ }^{16}$

${ }^{16}$ Consultar B-P (2007, p. 235). 
A fixação de preços é a política regulatória que B-P destaca - devido aos juros altos - para evocar a teoria da captura como explicação do desequilíbrio fiscal. Mas a hipótese da captura da política macroeconômica pela indústria financeira e pelos rentistas pode e deve, para que se avance em sua confirmação, investigar outros tipos de regulação, como a subvenção direta em dinheiro público propiciada pelo Programa de Estímulo à Reestruturação e ao Fortalecimento do Sistema Financeiro Nacional (Proer) etc. ${ }^{17}$ Como argumentado, o atual modelo macroeconômico originou-se na virada histórica propiciada pelo Plano Real, quando se estruturou a coalizão financeiro-rentista. B-P qualifica esse modelo como sendo a macroeconomia da estagnação, caracterizada por taxa de inflação baixa, taxa de juros de curto prazo elevada e taxa de câmbio sobrevalorizada.

A fixação de preços não é o único indício que nutre a hipótese da captura da política macroeconômica brasileira por grupos de interesse financeiro. O Quadro I constitui um exercícioexploratório de distinção de três grupos de fontes empíricas para pesquisas sobre a captura das políticas monetária, cambial e fiscal: indicadores econômicos; instituições econômicas e jurídicas e gestão pública; instituições políticas e política competitiva. Ela inclui alguns elementos, entre outros possíveis, em cada um desses grupos. A investigação da hipótese da captura da política macroeconômica requer um esforço de pesquisa interdisciplinar de economistas, cientistas políticos e sociólogos políticos, assim como uma perspectiva de análise sistêmica, no sentido de se apreender os múltiplos elementos que constituiriam um sistema de captura.

Quadro I: Fontes empíricas para pesquisas sobre captura do BCB e STN por grupos financeiros ${ }^{18}$

\begin{tabular}{|l|l|l|}
\hline \multicolumn{1}{|c|}{ Indicadores Econômicos } & $\begin{array}{l}\text { Instituições Econômicas e } \\
\text { Jurídicas e Gestão Pública }\end{array}$ & $\begin{array}{c}\text { Instituições Políticas } \\
\text { e Política Competitiva }\end{array}$ \\
\hline $\begin{array}{l}\text { Crescimento dívida pública/ } \\
\text { miB (1995-2003); caiu depois, } \\
\text { mas é superior à do período } \\
\text { pré-estabilização (1991-1994) }\end{array}$ & $\begin{array}{l}\text { Insulamento burocrático do } \\
\text { CMN versus proximidade } \\
\text { institucional entre BCB } \\
\text { e grupos financeiros }\end{array}$ & $\begin{array}{l}\text { Delegação de poderes do } \\
\text { Congresso Nacional (CN) ao } \\
\text { CMN e ao BCB - e.g, } \\
\text { Lei 9.069/1995 e Emenda } \\
\text { Constitucional 40/2003 }\end{array}$ \\
\hline $\begin{array}{l}\text { Volumosa arrecadação de } \\
\text { superávit primário, sobretudo } \\
\text { desde 1999 }\end{array}$ & $\begin{array}{l}\text { Centralização da autoridade } \\
\text { monetária no BCB }\end{array}$ & $\begin{array}{l}\text { Demais medidas legislativas de } \\
\text { interesse do capital financeiro } \\
\text { no CN, e.g. Lei Complementar } \\
\text { 109/2001 (previdência } \\
\text { privada) }\end{array}$ \\
\hline
\end{tabular}

\footnotetext{
${ }^{17}$ O Proer foi instituído em 3/11/1995, pela Medida Provisória n. 1.179 e Resolução n. 2.208.

${ }^{18}$ Entre outras fontes, a tabela baseia-se em Cintra (2005); Monteiro (2006b); Unafisco Sindical (2007); Pochmann (2003 e 2005); Oliveira (2003); Santos e Patrício (2002); Ferreira (2005); Loureiro (1997); Rua (1997); Lima (2005); Sola, Kugelmas e Whitehead (2002). Consultar também glo.bo/1QIKXmh (acesso em 8/3/2016).
} 


\begin{tabular}{|c|c|c|}
\hline $\begin{array}{l}\text { Elevação da carga tributária } \\
\text { (1993-2007) }\end{array}$ & $\begin{array}{l}\text { Vínculos profissionais duplos } \\
\text { da alta burocracia do BCB } \\
\text { (migram do setor público } \\
\text { para privado e vice-versa) }\end{array}$ & $\begin{array}{l}\text { Padrão de accountability de } \\
\text { política monetária atualmente } \\
\text { existente }\end{array}$ \\
\hline $\begin{array}{l}\text { Tendência de sobrevalorização } \\
\text { do real (desde 1994) }\end{array}$ & $\begin{array}{l}\text { Vínculos do FMI com as } \\
\text { autoridades monetária, } \\
\text { cambial e fiscal brasileiras }\end{array}$ & $\begin{array}{l}\text { Participação do capital } \\
\text { financeiro no financiamento } \\
\text { de campanhas eleitorais }\end{array}$ \\
\hline $\begin{array}{l}\text { Elevada taxa básica de juros } \\
\text { desde } 1994\end{array}$ & $\begin{array}{l}\text { Política regulatória do BCB } \\
\text { e da CVM; abertura do } \\
\text { setor bancário ao capital } \\
\text { estrangeiro, e.g. }\end{array}$ & $\begin{array}{l}\text { Presença dos grupos } \\
\text { financeiros no CN } \\
\text { e nos partidos }\end{array}$ \\
\hline $\begin{array}{l}\text { Elevados spreads e tarifas } \\
\text { bancárias }\end{array}$ & $\begin{array}{l}\text { Programa de Estímulo } \\
\text { à Reestruturação e ao } \\
\text { Fortalecimento do Sistema } \\
\text { Financeiro Nacional (Proer) }\end{array}$ & $\begin{array}{l}\text { Enfoque da grande mídia (ator } \\
\text { relevante do sistema político) } \\
\text { ao desequilíbrio fiscal não o } \\
\text { relaciona aos juros elevados }\end{array}$ \\
\hline Concentração bancária & $\begin{array}{l}\text { Agências de RI e análise de } \\
\text { outras agências do BCB } \\
\text { e do Ministério da Fazenda }\end{array}$ & \\
\hline $\begin{array}{l}\text { Aumento dos lucros dos } \\
\text { bancos versus baixa } \\
\text { arrecadação tributária das } \\
\text { entidades financeiras }\end{array}$ & Programa Best & \\
\hline $\begin{array}{l}\text { Forte aumento da renda das } \\
\text { empresas financeiras vis-à-vis } \\
\text { as não-financeiras }\end{array}$ & $\begin{array}{l}\text { Sistema de Pagamentos } \\
\text { Brasileiro (SPB) }\end{array}$ & \\
\hline $\begin{array}{l}\text { Elevação da participação do } \\
\text { setor financeiro no PIB }\end{array}$ & $\begin{array}{l}\text { Alterações no Código } \\
\text { de Processo Civil }\end{array}$ & \\
\hline $\begin{array}{l}\text { Crescimento dos milionários } \\
\text { no Brasil }\end{array}$ & $\begin{array}{l}\text { Nova lei das Sociedades } \\
\text { Anônimas }\end{array}$ & \\
\hline $\begin{array}{l}\text { Lucro financeiro de empresas } \\
\text { do setor produtivo maior que } \\
\text { o operacional }\end{array}$ & Lei da lavagem de dinheiro & \\
\hline
\end{tabular}

Fonte: Elaboração do autor.

Considera-se aqui o BCB, a STN e a CVM como agências reguladoras, ao menos no lato sensu (Monteiro, 2006 ; Cardim de Carvalho, 2002). A CVM exerce claramente a função de órgão regulador. Embora o BCB seja formalmente uma instituição supervisora do SFN, ele, lato sensu, também é uma agência reguladora, pois secretaria o órgão normativo, o Conselho Monetário Nacional (CMN), que, por sua vez, conforme a Lei 4595/64, regula os valores interno e externo da moeda, o equilíbrio do balanço de pagamentos e as instituições financeiras públicas e privadas. Por fim, a STN administra a dívida pública (interna e externa). Posner (2004, p. 50) define o conceito mais amplo de regulação econômica, como "o padrão de 
intervenção estatal no mercado [...] que [...] se refere a todos os tipos de impostos e subsídios, bem como aos controles legislativo e administrativo explícitos sobre taxas, ingresso no mercado, e outras facetas da atividade econômica". A função de regulação econômica é mais ampla que a forma institucional de agências regulatórias independentes que seu exercício pode assumir. ${ }^{19}$

Se a teoria da captura da política regulatória fornece uma trilha plausível para explorar o problema levantado neste artigo, como operacionalizar metodologicamente essa investigação diante de tantas variáveis? É o que será visto a seguir. Como dito, não se pretende submeter a teste conclusivo a hipótese da captura do $\mathrm{BCB}$, mas apenas contribuir para reforçar sua plausibilidade. O problema é complexo, envolve, como esboçado no Quadro I, variáveis inter-relacionadas e mais pesquisa.

Quanto às abordagens neoinstitucionalistas, elas adquiriram status explicativo relevante em pesquisas empíricas de ciência política, relações internacionais e economia (Hall e Taylor, 2003). Auxiliam na compreensão do comportamento dos atores políticos, que não atuam no vácuo, mas inseridos em instituições. Young $(1989$, p. 32) define instituições como "social practices consisting of easily recognized roles coupled with clusters of rules or conventions governing relations among the occupants of these roles". Instituições podem envolver ou não organizações, estas consideradas enquanto "material entities possessing physical locations (or seats), offices, personnel, equipment, and budgets". Nesse sentido, o mercado é uma instituição e a firma é uma organização (Tallberg, 2005).

Este trabalho argumenta que as agências de RI no BCB e na STN e a criação da agência Best Brazil evidenciam que a indústria financeira aloca seus recursos de poder com a efetividade suficiente para influenciar as ações dos atores nas instituições reguladoras e as decisões políticas.

\section{A INSTITUCIONALIZAÇÃO DAS RELAÇÕES COM INVESTIDORES}

Nos anos 1990, a globalização financeira se fez acompanhar de crises financeiras e cambiais de grande envergadura internacional nos mercados emergentes ${ }^{20}$ : México (1994-1995), Ásia (1997), Rússia (1998) e Brasil (1999) (Eichengreen, 2000, pp. 235-247; Stiglitz, 2007, pp. 353-379). ${ }^{21}$ Tais crises suscitaram várias políticas

\footnotetext{
${ }^{19}$ A esse respeito, consultar Melo (2000). Em uma avaliação das agências reguladoras feita em 2006 pelo IDEC (Instituto Brasileiro de Defesa do Consumidor) o BCB, junto com a ANS, recebeu a pior nota.

${ }^{20}$ Globalização financeira é " a interação de três processos distintos ao longo dos últimos vinte anos: a expansão extraordinária dos fluxos financeiros internacionais, o acirramento da concorrência nos mercados internacionais de capitais e a maior integração entre os sistemas financeiros nacionais" (Baumann, Canuto e Gonçalves, 2004, p. 221)

${ }^{21}$ A crise asiática atingiu Coréia do Sul, Tailândia, Indonésia e Malásia. Na crise de 2008, a imediata operação governamental, nos EUA, para tentar salvar o sistema financeiro só reforça a preocupação
} 
da comunidade financeira internacional visando reduzir suas intensidades e frequências e fortalecer o sistema financeiro de modo mais global. O objetivo geral delas é construir uma estrutura institucional para prevenir e resolver crises. Nas diversas etapas dessas policies estão envolvidas organizações multilaterais - como FMI, Banco Mundial, G-7 e G-2022 -, agências econômicas de Estados nacionais e organizações nacionais e globais do setor financeiro privado, como o Institute of International Finance (IIF), que, junto com o FMI, tem apoiado tecnicamente a institucionalização de relações com investidores pelos governos de países emergentes e feito avaliações sistemáticas dos programas criados.

Entre as principais políticas desde então implementadas, destacam-se os padrões e códigos internacionalmente aceito ${ }^{23}$, os programas de relacionamento com investidores (PRIs) e as cláusulas de ação coletiva(CACs) ${ }^{24}$.

A origem das RI está nas comunicações corporativas. Elas são um campo específico das relações públicas, dirigido ao mercado de capitais e ao comportamento dos investidores. ${ }^{25}$ Os programas governamentais de RI institucionalizam, com mais efetividade, vínculos do setor privado com as áreas do setor público que regulam a moeda, o câmbio, o crédito e as finanças.

Os PRIs alocam recursos políticos do Estado para os grupos financeiros, como informação ágil e de qualidade. ${ }^{26}$ Esses programas institucionalizam canais de informação e comunicação de mão dupla entre agências governamentais das áreas monetária e fiscal e grupos de interesse financeiro (inter)nacionais.

Segundo os principais fomentadores e formuladores dessa onda de institucionalização de RI em agências governamentais de países emergentes, nos anos 1990, tal empreendimento estratégico tem dois objetivos: ajudar as autoridades públicas a conhecerem as percepções dos investidores e fornecerem ao mercado feedback sobre as mudanças de políticas. ${ }^{27} \mathrm{Em} 2002$, o IIF formulou indicativamente e publicou para a comunidade financeira internacional as diretrizes mínimas para RI em mercados emergentes (IIF, 2002, p. 52).

desse trabalho com os vínculos desequilibrados do Estado, em muitos países, com as grandes corporações financeiras.

${ }^{22}$ Consultar G-2- "Communiqué" (2004), G-20 Communiqué (2004) e Principles for Stable Capital Flows and Fair Debt Restructuring in Emerging Markets (2004), disponíveis respectivamente em bit. ly/1Lbtciz, bit.ly/1TI32qG e bit.ly/1UQ37aK(acesso em 8/3/2016).

${ }^{23}$ A estrutura de padrões e códigos abrange doze áreas divisíveis em três grupos: policy transparency, regulação e supervisão do setor financeiro e integridade de mercado. Consultar bit.ly/1M6cyMb , acesso em 9/3/2016.

${ }^{24}$ CACs são mecanismos que permitem a um grupo majoritário de detentores de títulos aprovar uma reestruturação de dívida que legalmente passa a comprometer todos os demais credores, mesmo os que tenham se posicionado contra tal reestruturação.

${ }^{25}$ Para uma visão geral das relações com investidores, consultar Mahoney (2007). Um panorama do atual desenvolvimento das RI no setor privado brasileiro encontra-se em Soares (2007, pp. 25-42).

${ }^{26}$ Consultar Dahl (2005, pp. 91-92) e Mancuso (2007, p. 81).

${ }^{27}$ Consultar Action Plan (IIF, p. 2002, p. 17), disponível em www.iif.com/emp/article+356.php 
O Brasil, além de ser o único país emergente que possui dois programas de RI, é um dos poucos onde tais empreendimentos preenchem, com êxito, as diretrizes mínimas. A literatura mais recente sobre o FMI considera que atores não governamentais, como os grupos financeiros internacionais, têm poder para influenciar a modelagem dos programas dessa organização multilateral (Vreeland, 2004).

A institucionalização das RI no BCB e na STN iniciou-se em 1999, em resposta à crise que levou à desvalorização do real, quando a âncora cambial foi substituída pelo câmbio flutuante e pelo regime de metas de inflação. ${ }^{28}$ Nesse contexto de mudanças nas políticas cambial e monetária, criou-se, primeiramente, a Gerência Executiva de Relacionamento com Investidores do BCB, que passa a ser analisada na próxima seção. ${ }^{29}$

\section{Gerência Executiva de Relacionamento com Investidores do Banco Central ${ }^{30}$}

No segundo semestre de 1998, na esteira da crise financeira que levou a Rússia à moratória, o mercado emergente brasileiro foi a "bola da vez" na crise de confiança generalizada dos investidores, enfrentando fuga de capitais e perda de reservas internacionais. Governo brasileiro e FMI acertaram, no final daquele ano, um pacote preventivo de apoio financeiro, totalizando US\$ 41,5 bilhões, que previa, como contrapartida, elevação das taxas de juros de curto prazo e aperto fiscal. Mesmo assim, em janeiro de 1999 a âncora cambial, ainda vigorando, continuou a ser posta à prova por agentes do mercado, resultando em desvalorização do real, flutuação do câmbio - ou seja, derrocada do câmbio fixo - e substituição da diretoria do BCB (Bogdanski, Tombini e Werlang, 2000).

A nova direção do BCB decidiu implantar, como âncora nominal alternativa à cambial, o regime de metas para a inflação. Nesse regime, o controle da inflação é o principal objetivo da política monetária, que passa a ser perseguido por uma estrutura institucional denominada, em inglês, inflation targeting. Em 4 de março, data da posse da nova diretoria, realizou-se a $33^{\text {a }}$ Reunião do Comitê de Política Monetária (COPOM), em cuja ata consta o seguinte:

“[...] foi decidido, por votação unânime, que [...] a gestão da política monetária passaria a ser feita, primariamente, pela definição da meta da Taxa SELIC e do seu eventual viés para o período entre reuniões ordinárias do COPOM; [...] a meta da Taxa SELIC foi fixada em $45 \%$ a.a., e o seu viés foi de redução" (BCB, 1999).

Ou seja, a taxa de juros alcança o status de principal instrumento de política monetária antes mesmo da implantação formal do regime de metas para a inflação. ${ }^{31}$

\footnotetext{
${ }^{28}$ Consultar "Nota Explicativa da Decisão do Copom de 04/03/1999”, disponível em bit.ly/1Ut0rj1, acesso em 14/3/2016.

${ }^{29}$ O sistema de metas de inflação foi instituído pelo Decreto 3.088, de 21/6/1999, do Presidente da República.

${ }^{30}$ Consultar www.bcb.gov.br/?INVEST.

${ }^{31}$ Observe-se em passant a então elevadíssima meta da taxa básica de juros.
} 
Bogdanski, Tombini e Werlang (2000, p. 9) - três formuladores do inflation targeting no Brasil - atestam o papel decisivo que a nova direção do BCB, respaldada pelo FMI, teve na persuasão das principais autoridades do Governo Federal sobre a necessidade de implementar as metas de inflação. No Memorando de Política Econômica, dirigido pelo governo brasileiro ao FMI, lê-se:

"O objetivo primordial da política monetária é garantir índices baixos de inflação. O Banco Central pretende adotar um sistema viável de metas inflacionárias formais com a maior brevidade possível. Como primeiro passo nesse processo o Governo fará uma revisão do anteprojeto de lei agora em discussão no Congresso Nacional que trata do Banco Central e outras instituições financeiras com vistas a fortalecer a independência operacional do Banco Central no desempenho de sua missão anti-inflacionária. A proposta revisada incluirá: procedimentos para a definição de uma meta anual de inflação bem como para a prestação de contas ao Congresso a respeito dos progressos alcançados nessa tarefa; mandatos fixos para o Presidente e diretores do Banco Central; e uma forma apropriada de quarentena para os membros da Diretoria do Banco ao se desligarem de suas funções. Além disso o Banco Central pretende beneficiar-se de experiências estrangeiras relevantes no estabelecimento da infraestrutura técnica necessária ao sistema de definição de metas formais para a inflação. Com esse propósito solicitou a assistência do Departamento de Assuntos Monetários e Cambiais do FMI para organizar (em cooperação com os bancos centrais de países que utilizam sistemas similares) um seminário em Brasília no mês de abril para discutir os principais assuntos nessa área" (grifos do autor). ${ }^{32}$

Esse memorando é relevante por mostrar: a coparticipação política e técnica do FMI (ou seja, comunidade financeira internacional), em sintonia com o BCB, na implementação das metas de inflação; a vinculação da nova política monetária anti-inflacionária à meta de fortalecimento da independência operacional do $\mathrm{BCB}$ vis-à-vis os Poderes Executivo e Legislativo; que a independência da Autoridade Monetária seria compensada com um novo mecanismo de prestação de contas do $\mathrm{BCB}$ ao Congresso Nacional. ${ }^{33}$

Nesse contexto, o BCB passa por reformas visando a uma estrutura institucional específica para a nova política monetária. No âmbito da Diretoria de Política Econômica, o recém-empossado Sérgio Werlang, um dos policymakers brasileiros

\footnotetext{
${ }^{32} \mathrm{O}$ memorando, de 08/03/99, está em bit.ly/1UdVAC9 (acesso em 9/3/2016). O primeiro seminário internacional sobre o sistema de metas de inflação ocorreu em 3/5/1999, passando a ser realizado anualmente pelo BCB.

${ }^{33}$ A legislação a que o Memorando se refere é o PEC-21/1997, mudado, então, para PEC-53/1999. A Emenda Constitucional 40/2003, aprovada na gestão do ministro Antonio Palocci, concluiu a tramitação legislativa de alteração do Art. 192 da CF.
} 
do sistema de metas para a inflação, cria, imediatamente, o Departamento de Estudos e Pesquisas (Depep) e o Grupo de Comunicação Institucional (GCI), que, em 2002, passará a chamar-se Gerência Executiva de Relações com Investidores (Gerin). ${ }^{34} \mathrm{~A}$ nova política monetária tem intrínseca necessidade de se apoiar em mecanismos de transparência, accountability e comunicação em relação aos agentes de mercado (International Monetary Fund, 1999; Fraga et al., 2003).

Em pouco tempo, o GCI, hoje Gerin, tornou-se uma unidade específica do $\mathrm{BCB}$, ligada à Diretoria de Política Econômica. Seu staff é constituído por 10 funcionários (cinco economistas, dois administradores, um estatístico e um engenheiro), todos analistas concursados do $\mathrm{BCB}$, ingressos em concursos ocorridos de 1977 a 2002.

Entre as atividades da Gerin, destacam-se a elaboração da Pesquisa de Expectativas de Mercado, o Relatório de Mercado Focus, reuniões regulares com economistas-chefes dos principais bancos, respostas a solicitações do setor privado, participação nas reuniões do Comitê de Política Monetária (Copom) e no Best Brazil, apresentações a investidores e a organização do seminário internacional sobre metas para a inflação.

Não se avalia que a condução do regime de metas de inflação apoia-se apenas, ou mesmo principalmente, nas informações coletadas do setor financeiro privado. Mas é relevante associar ao menos dois elementos, na perspectiva sistêmica de investigação da hipótese da captura da política macroeconômica: a acentuada aproximação institucional, na política monetária, entre BCB e interesse financeiro; a avaliação de especialistas em análise política da política monetária, tal qual Wooley (1984), que observa como os bancos podem lucrar com os juros altos, mesmo em contexto de recessão dos demais setores, e o apego deles ao combate à inflação, pois, sendo credores líquidos, ela os prejudica.

O IIF, organização de interesse muito representativa da comunidade financeira global, e provida de efetivos recursos de poder, publicou, em 2005 e 2006, duas avaliações abrangentes de programas de RI. A de 2005 envolveu 30 países, selecionados de acordo com o nível de empréstimo tomado e projetado. ${ }^{35} \mathrm{~A}$ avaliação de 2006 abrangeu 32 países. ${ }^{36} \mathrm{E}$ foi feita mediante 20 critérios, que estão explicitados no Quadro II.

\footnotetext{
${ }^{34}$ Werlang é hoje diretor-executivo do Banco Itaú.

${ }^{35}$ Institute of International Finance (2005, p. 3).

${ }^{36}$ A avaliação publicada em 2008, referente a 2007, agregou mais seis países, todos da África Subsahariana, totalizando 38 (IIF, 2008). Nela, as Gerin do BCB e do TN obtiveram nota máxima em todos os quesitos, mantendo o Brasil como o país melhor avaliado pelo IIF em práticas de investor relations e data transparency. Este trabalho apoiou-se nas duas primeiras avaliações (2005 e 2006).
} 
Quadro II: Critérios de Avaliação de RI Adotados pelo IIF

\begin{tabular}{|c|c|}
\hline Best Practice & Critérios avaliados \\
\hline \multirow[b]{2}{*}{ Agências de RI/staff } & Presença de um PRI formal \\
\hline & $\begin{array}{l}\text { Staff de RI identificável e acessível através de } \\
\text { websites }\end{array}$ \\
\hline \multirow{3}{*}{ Website de RI } & $\begin{array}{l}\text { Websites do Banco Central e de agência governa- } \\
\text { mental disponível em Inglês }\end{array}$ \\
\hline & $\begin{array}{l}\text { Links recíprocos para Banco Central, Ministério } \\
\text { das Finanças e outros websites de agências } \\
\text { governamentais }\end{array}$ \\
\hline & $\begin{array}{l}\text { Capacidade dos investidores registraram-se no } \\
\text { website }\end{array}$ \\
\hline \multirow[b]{6}{*}{$\begin{array}{l}\text { Disseminação de dados macroeconômicos } \\
\text { e informação sobre políticas públicas }\end{array}$} & Adesão do país ao SDDS \\
\hline & $\begin{array}{l}\text { Efetiva transparência de dados relevantes para o } \\
\text { mercado }\end{array}$ \\
\hline & $\begin{array}{l}\text { Dados macroeconômicos apresentados em for- } \\
\text { mato marketfriendly }\end{array}$ \\
\hline & $\begin{array}{l}\text { Disponibilização de informações históricas } \\
\text { (políticas públicas e indicadores) }\end{array}$ \\
\hline & $\begin{array}{l}\text { Disponibilização de informações prospectivas de } \\
\text { políticas públicas }\end{array}$ \\
\hline & $\begin{array}{l}\text { Disponibilização de informação estrutural (legal, } \\
\text { regulatória) }\end{array}$ \\
\hline Lista de contatos de RI & Ativa lista de contado com investidores \\
\hline \multirow[t]{7}{*}{ Feedback e canais de comunicação } & Comunicação com investidores através da Web \\
\hline & Encontros bilaterais com investidores \\
\hline & Non-deal roadshows \\
\hline & Teleconferências com investidores \\
\hline & $\begin{array}{l}\text { Feedback dos investidores refletido em decisões } \\
\text { de políticas públicas }\end{array}$ \\
\hline & Sênior policymakers acessíveis aos investidores \\
\hline & $\begin{array}{l}\text { Disponibilização, nos websites, de arquivos de } \\
\text { apresentaçôes para investidores e de materiais de } \\
\text { teleconferências }\end{array}$ \\
\hline Auto-avaliação regular & Auto-avaliação regular dos PRIs \\
\hline
\end{tabular}

Fonte: IIF (2005, p. 15).

$\mathrm{Na}$ avaliação de 2005, a Gerin (BCB) alcançou o primeiro lugar no ranking dos 30 países avaliados, obtendo 33 dos 38 pontos possíveis. ${ }^{37} \mathrm{Na}$ de 2006 , que incluiu 32 governos de países emergentes, a Gerin (BCB) manteve-se em primeiro lugar, e ainda aumentou em um ponto sua nota (34/38), por ter avançado na im-

\footnotetext{
${ }^{37}$ Incluindo a Gerin (TN), que obteve $29 / 38$ pontos, o Brasil ficou, então, em primeiro lugar nas melhores práticas de RI, no ranking de 30 países avaliados pelo IIF, com $37 / 38$ pontos.
} 
plantação dos critérios supramencionados. $\mathrm{Na}$ avaliação de 2008 , referente às atividades de 2007, a Gerin (BCB) obteve a nota máxima (38/38).

\section{Gerência de Relacionamento Institucional do Tesouro Nacional ${ }^{38}$}

Além da Gerin (BCB), há, na Secretaria do Tesouro Nacional (STN), a Gerência de Relacionamento Institucional do Tesouro Nacional - Gerin (STN). Seu processo de implementação também remonta a 1999, embora ela tenha sido formal e efetivamente institucionalizada apenas em 2001. A concepção e o início da modelagem do que viria a ser a Gerin (STN) ocorreu, a princípio experimentalmente, no âmbito da COGEP (Coordenação Geral de Planejamento Estratégico da Dívida Pública), que é um dos departamentos da STN. Posteriormente, a Gerin foi institucionalizada como uma agência específica da COGEP.

Até 2004, a Gerin (STN) incumbia-se apenas da dívida pública interna e, assim, comunicava-se apenas com os investidores domésticos. Então, o BCB cuidava da dívida externa e sua Gerin fazia a comunicação de mão dupla com os investidores estrangeiros. Desde 2004, a gestão da dívida pública externa também passou para a responsabilidade da STN. Na atual divisão de tarefas da Administração Pública do Governo Federal, enquanto a Gerin (BCB) desempenha um papel mais geral de comunicação com os investidores sobre assuntos de política econômica e monetária, a Gerin (STN), de acordo com o regimento interno da STN, é responsável pelo relacionamento com participantes dos mercados financeiros, no que diz respeito às informações sobre a Dívida Pública Federal e ao financiamento dela; e por contribuir para a ampliação da base de investidores e manter contato com as agências de rating. ${ }^{39}$

O grupo de dealers da STN e do BCB, de dentro e fora do país, tem auxiliado na aquisição e implantação de equipamentos tecnológicos (Tesouro Nacional, 2005, p. 48). Exemplo: em dezembro de 2007, a STN realizou uma audioconferência com o patrocínio do banco francês BNP Paribas.

Ademais, no que diz respeito ao item II do mencionado Art. $26^{\circ}$ do regimento interno da STN, a Gerin mantém contato regular com agências de rating, visando obter uma melhor classificação de risco e captar recursos no mercado a custos menores no futuro e agenda e acompanha in loco suas visitas ao Brasil. ${ }^{40}$

A STN tem alcançado progressos na gestão da dívida pública. Mas, apesar dos reconhecidos avanços ocorridos nos últimos anos, o fato é que o endividamento público está em nível bem maior que o de 1994, quando se iniciou a estabilização monetária do Plano Real.

\footnotetext{
${ }^{38}$ Consultar bit.ly/1XclMMy (acesso 9/3/2016).

${ }^{39}$ O Regimento Interno da STN está em bit.ly/1LR0raT (acesso em 9/3/2016). De 2008 para cá, houve mudanças internas na STN. Algumas atribuições da Gerin passaram para outras agências do órgão.

${ }^{40}$ As principais agências de notação de risco de crédito são a Standard \& Poor's, Moody's Corp., Fitch Ratings e Merrill Lynch \& Co.
} 


\section{Brazil Excellence in Securities Transactions (Best)}

Outra importante iniciativa de RI na qual o BCB e a STN se envolveram nos últimos anos, não só através das duas Gerins, mas também de outros departamentos, é a Brazil Excellence in Securities Transactions (Best). Lançado em dezembro de 2004, o Best é uma associação conduzida conjuntamente por mercado e Estado, criada por iniciativa do setor privado. Compõe-se, na sua face empresarial, por ANBID (Associação Nacional dos Bancos de Investimento), BM\&F (Bolsa de Mercadorias e Futuros), BOVESPA (Bolsa de Valores de São Paulo) e CBLC (Companhia Brasileira de Liquidação e Custódia); pelo setor público, participam o BCB, a STN e a CVM.

Mas o Best é bem mais que um empreendimento privado-público de RI. Seu objetivo também é promover, com periodicidade anual, a infraestrutura dos mercados financeiro e de capital brasileiros para a comunidade internacional de investidores da Europa, América do Norte e Ásia, ou para qualquer pessoa ou entidade que possa "se tornar um opinion maker sobre o mercado brasileiro". Na denominação do IIF (2008), o Best diz respeito às Investment Promotion Agencies (IPAs). O principal idealizador do Best foi Pedro Luiz Guerra, atualmente um dos vice-presidentes da ANBID e diretor do Citibank. Ele não tem natureza jurídica e foi inteiramente custeado pela ANBID, BM\&F e Bovespa. Um de seus objetivos é consolidar os mercados de títulos públicos no Brasil e uma de suas motivações é "contribuir com a melhoria dos ratings atribuídos ao mercado brasileiro por meio da difusão de informações corretas e atualizadas". O Best faz roadshows nas principais praças financeiras do mundo, promove canais de comunicação e difusão de informações com a comunidade de investidores estrangeiros, identifica os principais problemas que lhes afetam e desenvolve soluções operacionais e regulatórias.

É racional avaliar, conforme faz o próprio Best, que os referidos avanços regulatórios e nos negócios com títulos públicos e renda variável tenham relação com essa atividade de RI e de promoção de investimentos financeiros envolvendo setor privado e setor público. Entre outros motivos, sobretudo de ordem estrutural, os avanços podem ser explicados pela influência dos grupos de interesse financeiro na política regulatória e pelo fato do aval governamental transmitir confiança aos investidores não residentes.

No último relatório de avaliação dos PRIs, envolvendo 38 países, o Institute of International Finance destaca o Best como uma prática recomendável e inédita, além de elogiar especificamente seu Practical Guide for International Investments in Portfolio (cujo nome oficial é Brazil Market Profile) (IIF, 2008, p. 27).

$\mathrm{O}$ vínculo institucional entre reguladores e regulados existente no Best é bastante acentuado e relevante para a economia política e a ciência política, particularmente numa investigação norteada pela teoria da captura da política regulatória. Além da ANBID, BM\&F, Bovespa e CBLC, esse guia conta também com o apoio institucional das outras seguintes organizações do setor privado: ANDIMA (Associação Nacional das Instituições do Mercado Financeiro), ANCOR (Associação Nacional das Corretoras de Valores, Câmbio e Mercadorias), ABVCAP (Associação 
Brasileira de Private Equity \& Venture Capital) e IBGC (Instituto Brasileiro de Governança Corporativa).

\section{CONSIDERAÇÕES FINAIS}

Pode-se avaliar, resumidamente, o seguinte:

- FMI e a comunidade financeira internacional, através do IIF, em convergência de interesses com a diretoria do BCB, influenciaram a institucionalização e o desenho das RI no BCB e na STN.

- A institucionalização de agências de RI no BCB e na STN materializa uma convergência de interesses entre os setores público e privado quanto ao provimento de um arranjo organizacional interativo apropriado às necessidades de informação-comunicação e ajustes mútuos demandadas nos negócios envolvendo investidores em ativos financeiros, sobretudo públicos, mas também privados, e autoridades estatais encarregadas da regulação monetária e fiscal.

- A agência de RI no BCB propicia um tratamento privilegiado, por parte da autoridade monetária, a grupos de interesse financeiro ao intercambiar-se com eles para prover-lhes e prover-se de canais de comunicação que disponibilizam informação tempestiva e de qualidade; induz a uma política monetária orientada pelo e para o mercado financeiro; e contribui para que as decisões estratégicas dos investidores se alinhem mais às do setor público $\mathrm{e}$ vice-versa.

- A agência de RI na STN institucionaliza, no âmbito da autoridade fiscal e das finanças públicas, a presença de grupos de interesse financeiros, propiciando-lhes informação estratégica para a realização de negócios envolvendo títulos da dívida pública. ${ }^{41}$

- Best Brazil expressa uma grande capacidade estratégica dos grupos de interesse financeiro utilizarem seus recursos de poder para envolver o Estado em parceria para a promoção e venda de produtos financeiros brasileiros para não residentes, no mercado internacional, assim como para a obtenção de políticas regulatórias.

O trabalho apresentou dados e evidências empíricas que revelam uma aproximação, de natureza relevante para a economia política e a ciência política, do BCB e do TN em relação aos poderosos grupos de interesse financeiro nacionais e internacionais, inclusive através da mediação do FMI. Detectou-se a participação da comunidade financeira internacional e nacional na criação, nas atividades, em par-

\footnotetext{
${ }^{41}$ Isso não necessariamente implica na piora da relação dívida pública/PIB. Nem a melhora desse indicador, por si só, nega a hipótese da captura, que se apoia, sobretudo, nas altas taxas de juros.
} 
te do patrocínio das necessidades operativas e em avaliações institucionais das agências de RI do BCB e da STN.

\section{REFERÊNCIAS BOBLIOGRÁFICAS}

ARIDA, P., BACHA, E. L. e LARA RESENDE, A. (2005) "Credit, interest, and jurisdictional uncertainty: conjectures on the case of Brazil". Instituto de Estudos de Politica Econômica, Casa das Garças: Rio de Janeiro, disponível em www.econ.puc-rio.br/PDF/seminario/2004/Paper\%20Edmar\%20Bacha.pdf, visitado em 15/03/2008.

BAUMANN, R. CANUTO, O. e GONÇALVES, R., (2004) Economia Internacional, Teoria e Experiência Brasileira. Rio de Janeiro: Campus.

BOGDANSKI, J., TOMBINI, A. A. e WERLANG, S. R. da C. (2000) "Implementing Inflation Targeting in Brazil", Working Papers Series, $\mathrm{n}^{\circ}$ 1, Banco Central do Brasil.

BRESSER-PEREIRA, L. C., (2007) Macroeconomia da Estagnação. São Paulo: Editora 34.

CAMDESSUS, M. (1995) The IMF and the Challenges of Globalization -The Fund's Evolving Approach to its Constant Mission, The Case of Mexico, Address at Zurich Economics Society, disponível em bit.ly/1UsTNsW (acesso em 14/3/2016).

CINTRA, M. A. M. (2005) “Suave Fracasso, A política macroeconômica brasileira entre 1999 e 2005". Novos Estudos - Cebrap, $\mathrm{n}^{\circ} 73$.

EICHENGREEN, B. (2000) A globalização do capital, uma história do Sistema Monetário Internacional, São Paulo: Editora 34.

FERREIRA, A. C. (2005) Os Donos da Dívida: um enfoque sociopolítico da dívida pública interna durante o governo FHC. Dissertação de Mestrado, Progr. Pós-graduação em Sociologia Política: UFSC.

FIESP The Brazilian economic - Recent performance and impact on the manufacturing industry, 2007, disponível em bit.ly/21rcyNL (acesso em 14/3/2016).

FISCHER, S. (2004) IMF Essays from a Time of Crisis, The International Financial System, Stabilization, and Development. Massachusetts Institute of Technology.

FRAGA, A., GOLDFAJN, I. e MINELLA, A. (2003) "Inflation targeting in emerging market economies", National Bureau of Economic Research, Working Paper 10019, bit.ly/1RZKvSW, MA: Cambridge (acesso em 14/3/2016).

FREITAS, M. C. P. de \& PRATES, D. M. (2001) “A abertura financeira no governo FHC: impactos e conseqüências”, Economia e Sociedade (17): 81-111.

G-20 Communiqué (2004), disponível em bit.ly/21PPZFM (acesso em 14/3/2016).

HALL, Peter A. e TAYLOR, Rosemary C. R. (2003) “As três versões do neoinstitucionalismo”. Lua Nova, $\mathrm{n}^{\circ} 58$.

IEDI. Importações, câmbio e indústria, a marcha da desindustrialização no Brasil, 2007, disponível embit.ly/1U10q7A (acesso em 14/3/2016).

INSTITUTE OF INTERNATIONAL FINANCE, INC. Action Plan of the IIF Special Committee on Crisis Prevention and Resolution in Emerging Markets, 2002.

INSTITUTE OF INTERNATIONAL FINANCE, INC. Investor Relations - An Approach to Effective Communication and Enhanced Transparency - Assessment of Key Borrowing Countries, 2005, disponível emwww.iif.com/emp/ir/, visitado em 12/01/2008.

INSTITUTE OF INTERNATIONAL FINANCE, INC. Investor Relations - An Approach to Effective Communication and Enhanced Transparency - Update of Key Borrowing Countries, 2006, disponível em www.iif.com/press/press+14.php, visitado em 01/03/2008.

INSTITUTE OF INTERNATIONAL FINANCE, INC. Investor Relations - An Approach to Effective Communication and Enhanced Transparency - Update of Key Borrowing Countries, 2008, disponível em www.iif.com/emp/article+57.php, visitado em 28/09/2008. 
INTERNATIONAL MONETARY FUND. Brazil, Selected Issues and Statistical Appendix”, Washington, D.C. International: Monetary Fund, 1999.

LIMA, S. R. F. (2005) “A autonomia do Banco Central do Brasil, as tensões que obstruíam a sua formalização no governo FHC”, Dissertação de Mestrado, UnB, 01/12/2005

LOUREIRO, M. R. (1997) Os economistas no governo. Rio: Editora FGV.

MAHONEY, W.F. (2001). The strategy and practice of investor relations. New York, NY: The NASDAQ Stock Market, Inc.

MANCUSO, W. P. (2007). O lobby da indústria no Congresso Nacional, empresariado e política no Brasil contemporâneo. São Paulo: Humanitas - Edusp

MELO, A. M. (2000) "Política Regulatória, Uma Revisão da Literatura”. BIB - Revista Brasileira de Informação Bibliográfica em Ciências Sociais, n 49, Rio: Anpocs.

MONTEIRO, J. V. (2006a) "Irrelevância da incerteza institucional e desempenho da economia". Revista de Administração Pública, Rio de Janeiro 40(3),503-12.

MONTEIRO, J. V.(2006b) "Intermediação política, transparência decisória e atendimentos preferenciais”. Revista de Administração Pública, Rio de Janeiro vol.40 n.4.

OLIVEIRA, F. de (2003) “O ornitorrinco", em Crítica à razão dualista - O ornitorrinco, São Paulo: Boitempo Editorial.

PAULANI, L. M. (2003) “Brasil Delivery: A Política Econômica do Governo Lula”, Revista de Economia Política, vol. 23, n 4 (92).

PAULANI, L. e TEIXEIRA, R. A. (2007) "O mais político dos temas econômicos”.Folha de S.Paulo, 10/2/2007.

POCHMANN, M. (2003) "O ciclo da financeirização e a distribuição funcional da renda no Brasil”. Jornal do Diap, Brasília.

POCHMANN, M. et al. (2005) Atlas da exclusão social, vol. 3, Os ricos no Brasil, São Paulo: Cortez.

POSNER, R. A. (2004) “Teoria da Regulação Econômica”. In MATTOS, P. (coord) - Prado, M. M. et alli (orgs.) Regulação Econômica e Democracia, S. Paulo: Editora 34. G-20, IIF and IPMA. Principles for Stable Capital Flows and Fair Debt Restructuring in Emerging Markets, 2004

SALISBURY, R. (1975) “Interest Groups”. In N. Polsby \& F. Greenstein, orgs.,Handbook of Political Science, Vol. 4, Boston: Addison-Wesley Publishing Company.

SAYAD, João (2005) “Dívida Pública: Quarenta Anos de Frustrações”. In Félix Mendonça, A Dívida Pública Brasileira. Brasília: Câmara dos Deputados, Conselho de Altos Estudos e Avaliação Tecnológica.

SOARES, G. (2007) "Prefácio - A Evolução da Atividade de RI no Brasil”. In MAHONEY, W. F. Manual do RI, Princípios e melhores práticas de Relações com Investidores, Rio: IMF Editora,.

SOLA, L., KUGELMAS, E. e WHITEHEAD, L. (2002) "Democratização, Estado e autoridade monetária num mundo globalizado - qual o lugar da política democrática? In. SOLA, L., KUGELMAS, E. e WHITEHEAD, L. Banco Central, autoridade política e democratização - um equilíbrio delicado, Rio: Editora FGV

STIGLER, G. J. (1971) “The Theory of Economic Regulation”. The Bell Journal of Economics and Management Science, Vol. 2, No. 1, pp. 3-21.

STIGLITZ, J. E. (2007) Globalização, como dar certo. São Paulo: Companhia das Letras

TESOURO NACIONAL (2005). Relatório Anual da Dívida Pública - 2004, Brasília.

UNAFISCO SINDICAL (2007). Arrecadação tributária em 2006: o paraíso dos bancos. Disponível em bit.ly/1RZLClC (acesso em 14/3/2016).

VREELAND, J. R. (2004) The International and Domestic Politics of IMF Programs. Yale University, 2004. Disponível em bit.ly/1Xqdzon (acesso em 14/3/2016). 